VIII. As to the Antagonism between Bromal Hydrate and Atropia.

In this investigation, thirty-six experiments were performed.

I. There is a distinct physiological antagonism between bromal hydrate and atropine.

2. After a fatal dose of bromal hydrate, the introduction of atropia arrests excessive secretion from the salivary glands and mucous surfaces of the lungs, and thus obviates the tendency to death from asphyxia caused by the accumulation of fluids in the air-passages. Atropia also causes contraction of the blood-vessels, and thus antagonises the action of bromal hydrate, which causes dilatation of these vessels by paralysis of the sympathetic nerve.

3. While atropia may save life after a fatal dose of bromal hydrate, the converse apparently loes not hold good, as we have never succeeded in saving life after a fatal dose of atropia by the subsequent injection of bromal hydrate.

In concluding this report, I feel it to be necessary to allude especially to the labours of two members of the Committee-viz., first, Dr. Alexander Bennett, who completely worked out the physiological actions of cocaine, theine, caffeine, and their allied compounds ; and, secondly, Dr. McKendrick, on whom the bulk of these researches ultimately devolved, and by whom the lengthened investigation on the antagonism between the sulphate of atropia and meconate of morphia was carried out. To him also we are indebted for the remarkable discovery of the antagonism between bromal hydrate and atropia. The long survey into which I have entered can convey no adequate idea of the many hours spent in laborious toil; of the skilful manipulation, sustained power of observation, judgment in inventing and comparing the results of experiments, and, I may add, patience under failures, which have characterised the efforts of these gentlemen. Even the account of the investigations themselves, with the tabulated results of the experiments, can give only a feeble conception of the laboratory work accomplished. The preparation of the report and its careful revision was in itself a work demanding no small time and labour.

I venture, however, to say that such are the toils and sacrifices required by modern medicine, if it be sincerely desired to solve existing difficulties, and prosecute those new inquiries which are so necessary for maintaining its position as a science and as an art. I sincerely trust that no parsimony nor error in administration will restrain the British Medical Association from continuing the noble efforts it has commenced, and rewarding by liberal grants the arduous labours of men who will dedicate themselves to these pursuits. It is gratifying to know that the present and, it is to be hoped, the future flourishing state of its finances, will enable it to take a lead in this patronage of scientific and practical endeavour for the benefit of humanity. I shall always esteem it a proud distinction for myself that I first indicated at least one method in which this could be accomplished,* and have demonstrated, in the two reports I have had the honour of laying before the Association, on the one hand, how error may be corrected, $\dagger$ and, on the other, how new fields may be acquired for the therapeutist in neutralising poisons and extending our means for the cure of disease.

\section{CASE OF IDIOSYNCRASY.}

THE following curious case of idiosyncrasy came under my notice lately. Mrs. R., aged 35, widow, a person of somewhat spare habit and active disposition, informs me that, since her early childhood, she has had a very strong aversion for potatoes. She knows no reason for this aversion; certainly it is not due to any fanciful notion. It is the result, apparently, of a peculiar idiosyncrasy. When she was quite a little creature, her uncle was very fond of playing a trick on her by concealing a small morsel of potato in a bit of butter, and inducing her to take it. The result always was very severe vomiting. She remembers her mother being very angry with her uncle on the occasion when he indulged in this practical joke. If she happened to be present where potatoes were being cooked, she became quite faint; and, until within a few years back, she could not even handle the tubers. At present, she would rather take the vilest medicines than taste a potato; indeed, she could not bring herself to do the latter. It is rather singular, that throughout life Mrs. R. has displayed an extraordinary susceptibility to febrile and "catching" diseases. Thus she states that, in her early childhood, she had hooping-cough, measles, scarlet fever, and since then small-pox, typhus fever, rheumatic fever, enteric fever, and lastly relapsing fever. Since suffering from relapsing fever, she has experienced some dyspnœa after exertion, and recently she had hæmoptysis. James W. Allan, M. B., Belford Hospital, Fort William, N.B.

* Researches into the Action of Mercury, Podophyllin and Taraxacum on the Biliary Secretion. Second edition. Edinburgh: Edmonston and Douglas, 8vo, 1874

+ See Address in Medicine for the year 1866, delivered at Chester.

\section{DESCRIPTION}

\author{
or $A$
}

\section{NEW PORTABLE.THERMO-ELECTRIC APPARATUS FOR MEDICAL AND PHYSIOLOGICAL INVESTIGATIONS.*}

By J. S. LOMBARD, M.D.,

Formerly Assistant Professor of Physiology in Harvard University, U.S.

AlTHOUGH many important facts regarding the general temperature of the body in disease have been ascertained of late years by the application of thermometers to clinical purposes, yet little or nothing has been done in the study of the temperature of different portions of the surface of the body as affected by morbid conditions of the internal organs. The reason of this is, undoubtedly, that it is only with thermoelectric apparatus that investigations of this kind can be properly made, and up to the present time all such apparatus has been of a nature to preclude its general employment by medical men. The writer has endeavoured, in the instrument to be described (see fig. I), to combine portability and compactness with sufficient delicacy for all clinical and many physiological investigations. He believes that a very little practice will enable any one to use the apparatus with ease and accuracy. Portions of the apparatus are not new, having been devised by the writer in 1866, and described by him in Archives de Physiologie, July 1868 .

The instrument may be divided into five parts-the galvanometer; the rheostat; the two thermo-piles; a tin kerosine lamp; and a brass stand, with a horizontal arm having a clamp at its end. Added to these are a compass and a magnifying glass. A board, three-tenths of an inch in thickness, and exactly fitting the interior of the box in which the apparatus is contained, with just sufficient allowance to permit of its being slid out at a door in one end, forms a second or false bottom to the box. The galvanometer, rheostat, lamp, and stand, are all on this board. The levelling screws of the galvanometer rest in holes in the board, and the rheostat also is secured to it. Calling the end of the box in which the door is the front, we have (fig.12) from before backwards, on the left, first, the ebonite base of the rheostat, four and two-tenths inches from left to right, and three inches from front to back; second, the galvanometer, four and four-tenths inches in diameter at its base. On the right, we have, first, the tin kerosine lamp; and, second, the brass stand. This completes the description of the arrangement of that portion of the apparatus which is on the board.

Both the galvanometer and the rheostat can be removed from the board; but it is not intended that they should be, except in case the mercury cups of the rheostat are to be emptied. In experimenting, the board, bearing on it the galvanometer, rheostat, lamp, and stand, is simply slid out at the door of the box; and the lamp and stand having been removed, the galvanometer and rheostat remain on the board as permanent fixtures.

The Galvanometer is constructed as follows. It has a circular; wooden base, the levelling screws of which rest (as before mentioned) in holes, or rather depressions, in the false bottom of the box. On this wooden base is screwed a square plate of ebonite, with rounded corners, so as to clear the groove in the wooden base in which the glass shade rests. On the plate of ebonite is fastened the frame on which the wire of the gaivanometer is wound. The frame is one and nine-tenths inches long, one inch wide, and one and one-twentieth inches high. It does not stand in the centre of the ebonite plate, but at one side. Placing the board (fig. 2) so that the rheostat is to the front, facing us, and, therefore, the galvanometer to the rear, the frame stands on the left hand edge of the plate (the observer's left hand), its length being from before backwards: the wire of the coil runs, therefore, in the same direction.

From each side of the frame two flat brass stanchions rise, converging towards a point over the centre of the slit in the coil, until at a height of two and one-tenth inches they are united by a brass platform, threetenths of an inch square. On this platform is a brass cylinder, threetenths of an inch high, covering the platform, with the exception of its four corners; and again on the cylinder, in the centre, is a split tube two-tenths of an inch long. Both cylinder and platform are pierced by a hole of the diameter of this split tube. In the split tube, and through the cylinder and platform, there slides a second tube with a milled head, and to the milled head inside this second tube is fastened one end of the fibre of unspun silk, which forms the suspension of the

* The instrument is made by William Ladd and Co., II and 12, Beak Street, Regent Street, London. 
needles, presently to be described. The attachment of the fibre to the milled head is made by passing the fibre through a small hole in the milled head, and then inserting into the hole a little wooden plug, by which the fibre is firmly clamped.

The so-called "needles" are made on the principle of those in the galvanometers of Sir William Thomson, consisting of two light flat pieces of steel, not quite half an inch long and three-twentieths of an inch in breadth. They are joined, with opposed poles, by a slender rod of aluminium. The upper needle is purposely magnetised the more strongly of the two, so that the system remains in, or nearly in, the meridian, the north pole of the upper needle pointing north. The upper needle is pierced at its centre by an aluminium wire, which constitutes the "index" of the galvanometer. The length of this wire, on the split tube of brass through its centre, and this split tube slides with slight friction on a brass rod six inches long, ending at one extremity in a cap with one side split, which cap fits over the milled head and brass cylinder before mentioned, resting on the uncovered corners of the brass platform. A hole in the top of the glass shade of the galvanometer permits the passage of the cap. The magnet is four-tenths of an inch wide, and the distance between its poles is three and threetenths inches. When in the box, the magnet and rod are secured to the inside of the door.

The Rheostat is constructed on the plan of a larger one devised by the writer in 1866, and described, with figures, in the Archives de Physiologie, July I868. At the left hand back corner of the ebonite block forming the base of the rheostat (fig. 2) are two binding-screws, in which

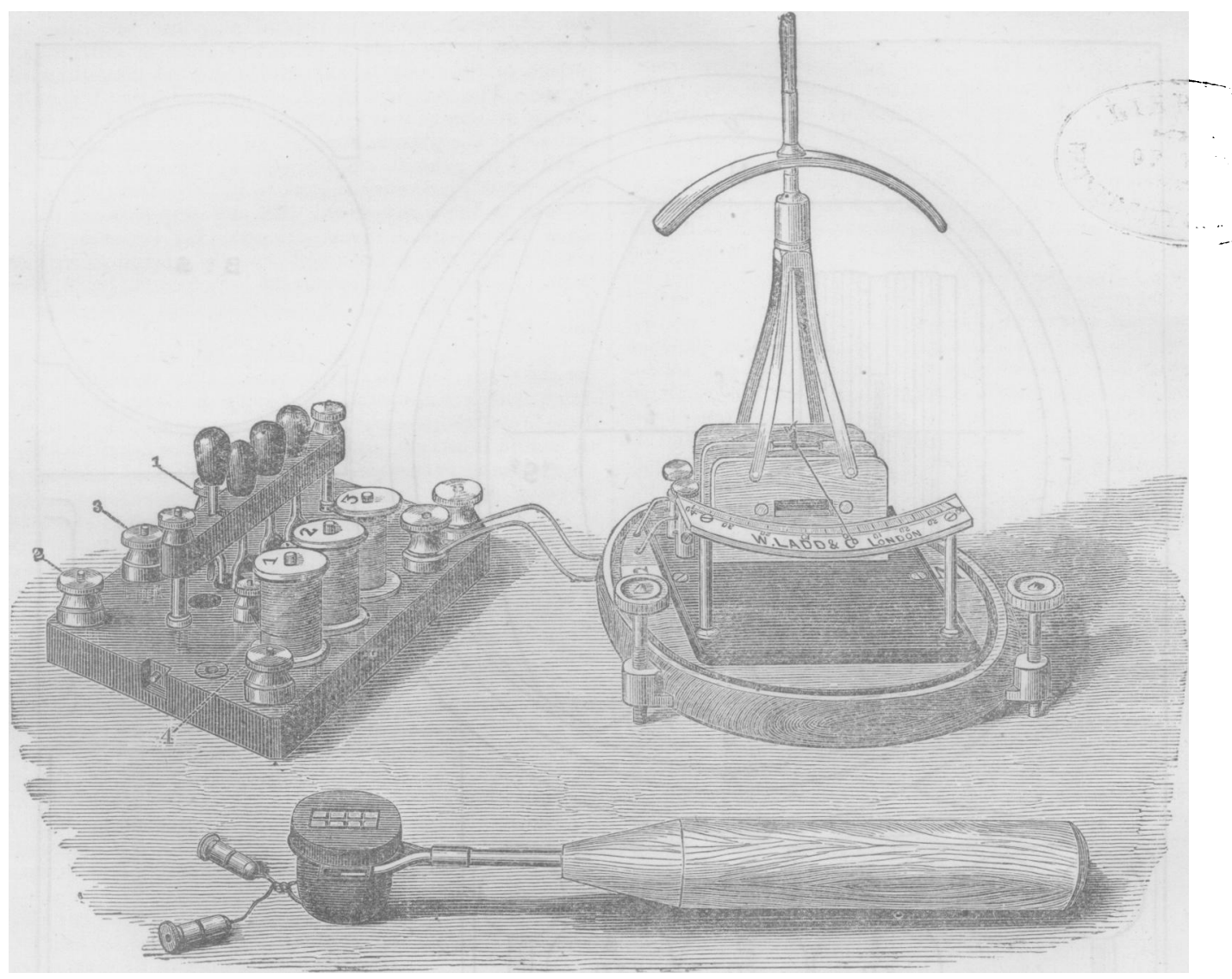

Fig. r.

right hand side, is two and three-tenths inches. It gradually tapers to a fine point, and is blackened at its end. On the left hand side the wire projects only eight-tenths of an inch ; and, therefore, to establish equilibrium, this end is much thicker than the other. The axis of the index is thus at right angles to that of the needles; and, on account of the length of the index, deflections of the needles-too slight to be observed directly - can be easily detected. On the ebonite plate, on the right hand side, is placed the scale, which consists of an arc of wood, covered with a similar arc of cardboard, graduated, resting on two brass pillars, which are screwed into the ebonite. The scale is graduated to 40 deg. on each side of the $0^{\circ}$; but the brass stanchions prevent the index from going farther than $30 \mathrm{deg}$., and in actual work the scale is not used above $25 \mathrm{deg}$, as beyond this point the proportionality between the degrees of the scale and the forces impelling the needles ceases. Up to 25 deg., however, the error is so slight that it may be neglected. Each degree of the scale is divided into halves; and as it is easy to read between the halves even with the naked eye, we can read to quarters of a degree. The object of the magnifying glass is to facilitate this reading. Our scale of $25 \mathrm{deg}$. is therefore divided into one hundred parts. The only portion of the galvanometer which remains to be described is the regulating magnet. This magnet, which is somewhat curved (the convexity of the curve being upwards when the magnet is adjusted), has a are fixed the ends of the two wires coming from the galvanometer. On the front of the ebonite base are three more binding-screws, numbered r, 3, and 2, from left to right; and at the right hand back corner is another binding-screw, marked 4. Nos. 2 and 4 are both on the right hand side of the base, in opposite corners, and are connected by a stout piece of copper let into the under side of the base. A similar connection joins Nos. 4 to the right hand of the two binding-screws which receive the terminals of the galvanometer; hence Nos. 2 and 4 are connected with each other, and with one end of the wire of the galvanometer. As regards the other two binding-screws, Nos. I and 3 , the disposition is different. Immediately behind these binding-screws is a row of five mercury cups, cut out of the thickness of the ebonite base. At each end of the row of cups is a small brass pillar, which at the height of four-tenths of an inch terminates in a flat surface, from the centre of which rises a rod seven-tenths of an inch long, the lower half of which is smooth, but the other half cut into a screw. A stout ebonite bar, three and three-tenths inches long, and four-tenths of an inch wide and deep, with a hole cut in each end, connects the two pillars; the rods of the latter passing through the holes in the bar, and the flat surface of the pillars forming a support for the bar to rest upon. The screw portion of the rods projects above the upper surface of the bar; and a thumb-screw at each end, which works down firmly 
on to the bar, keeps the latter steadily in place. The bar, therefore, passes directly over the row of mercury cups, its lower edge being fourtenths of an inch above the upper surface of the base. In the bar over the spaces between the cups are four holes: through these holes pass stout copper wires, with ebonite knobs on their upper ends. At a distance of seven-tenths of an inch from the knobs these wires bifurcate, forming two prongs, about four-tenths of an inch asunder, each prong dipping into a mercury cup, and thus forming a bridge from one cup to another. Of course, the three centre cups have each two prongs immersed in them, from two separate copper stems. By means of the knobs, the prongs can be lifted out and immersed at pleasure. In order to keep the prongs from falling back into the cups by their own weight when lifted out, each copper stem has on its side a little projection, which does not prevent the raising or lowering of the prongs, so long as the projection points to the right along the axis of the bar, a small slot being cut from the holes into the ebonite on that side through which the projection passes. When, however, the prongs having been raised from the cups, the knob is turned so that the projection is no longer over the slot, the stem cannot descend, the projection resting on the bar and preventing this. The first mercury-cup on the left communicates with the left hand of the two binding-screws which are connected with the galvanometer. The communication is effected like that previously described for binding-screws Nos. 2 and 4 . With the second mercurycup (counting from left to right), binding-screw No. I is connected, the

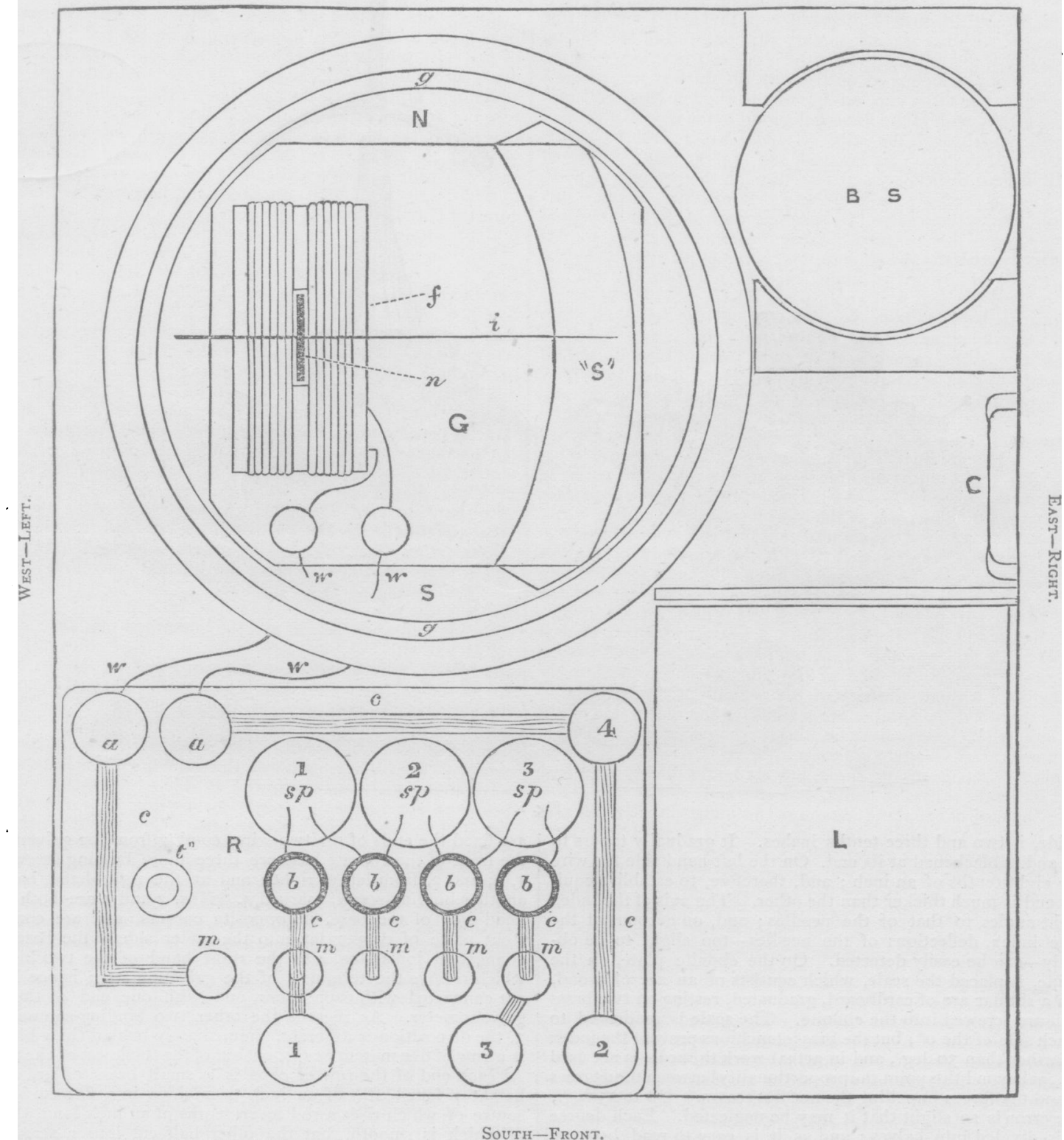

G. Galvanometer. "s." Scale of same. $f$. Frame on which is wound coil. $n$. Points to upper needle. $i$. Index. $g$. Groove in which fits glass shade. $w w$. Wires from galvanometer to rheostat.

R. Rheostat. I sp., 2 sp., 3 Sp. Resistance bobbins. $6, b, b, b$. Binding.screws, to which are attached the terminals of the resistance-coils, and which connect with the mercury cups in front of them. $m \mathrm{~m} \mathrm{~m} \mathrm{~m} \mathrm{~m}$ Mercurv-cups. Circles $x, 2,3,4$ (from left to right). Binding-screws with which thermopiles are connected. a, $a$. Binding-screws, to which wires from galvanome- ter are attached. $c, c$, . Copper connections. $t$. Thumb-screw, by which L. rheostat

B. S. Brass stand.

C. Compass.

All currents entering at binding-screws 2 and 4 of rheostat, cause the index of the galvanometer to move north ; and all currents entering at Nos. I and 3, cause the index to move south 
connection being made in the same manner as in the previous cases. When, therefore, the first knob on the left is lowered, its prongs establish a communication between binding-screw No. I and the left hand galvanometer binding-screw. Binding-screw No. 3 communicates with the last mercury-cup on the right ; and consequently it is evident that in order to connect it with the left hand galvanometer binding-screw, all the knobs must be lowered.

Next, as regards the resistance coils of the rheostat. Behind the mercury-cups is a row of small binding-screws, four in number, one behind each cup, except the first on the left. Behind these small binding-screws are three wooden spools, nine-tenths of an inch high, placed en end, on brass pegs, to keep them steady; and on these spools the wires constituting the resistances are wound. Each end of the wire of a spool is held by one of the four small binding-screws, and each binding-screw is connected (in the manner already described) with the mercury-cup in front of it. Spool No. I (counting from the left) has one end of its wire at the first binding-screw on that side ; and as this latter is connected with the second mercury-cup, one end of the coil on this spool communicates with this cup; the other end is attached to the second binding-screw, which is connected with the third cup. Hence a current arriving at the third cup, on its way to the left hand galvanometer binding-screw, will, if the knob belonging to the second and third cups be raised, pass through the wire on spool No. I, and thus reach the second cup. If the knob be lowered, the current will, of course, take the path of least resistance, and pass through the prongs. Spools Nos. 2 and 3 act in precisely the same way. It will be noticed, however, that only binding-screw No. 3-speaking now of the four original large binding-screws-is concerned in these resistances, for No. I communicates directly with the second cup, and is not at all affected by the raising or lowering of any of the knobs, except the first on the left. It will also be noticed that this first knob, when raised, cuts off completely all communication between both Nos. I and 3 and the left hand binding-screw of the galvanometer : it acts, therefore, simply as a "key".

The two Thermo-Piles consist each of eight pairs of bismuth and an alloy composed of 64.43 parts of antimony and 35.57 of zinc in 100 by weight. This alloy, with many others, is the result of a long and elaborate series of researches in thermo-electricity, made some years since by Mr. Moses G. Farmer of Boston, Massachusetts. It has an electromotive force nearly four times that of antimony. The pairs are fitted into ebonite caps, eight-tenths of an inch in height, and eight-tenths of an inch in diameter, measured on the bottom of the cap, where one face of the pile is exposed. The poles of the piles terminate in copper wires, which come out at the top of the ebonite caps and end in small binding screws. The binding-screw connected with the alloy end of the pile is marked on its side with the plus sign. Each pile has a metallic ring round it, with slits in it, through which tapes may be passed, and the pile secured to any part of the body. Each pile is also provided with a wooden handle, in and out of which slides a brass rod with a claw at one end. The pile fits into this claw, and, the wooden handle being held by the experimenter, the face of the pile may be applied to the surface of the body without the risk of the warmth of the hand interfering. The piles and the handles are secured to the under side of the top of the box, which swings back on hinges.

The lamp and brass stand require but little explanation. The lamp is of tin, and its dimensions are three and six-tenths inches in length by two and six-tenths inches in width, and one and nine-tenths inches in height. The foot of the stand measures two inches in diameter ; its stem is four inches and a quarter high, and on this stem slides a horizontal rod six inches and a quarter long, bearing at its end a screw clamp. The use of the lamp and the stand will be explained further on.

There remain in the box merely the compass, lens, and conducting wires, which require no special description. The box itself is eight and seven-tenths inches long, by seven and seven-tenths inches wide, and five and seven-tenths inches deep, outside measurements. As before stated, it opens both at one end and at the top. A handle is affixed to the top, by which it may be carried.*

Directions for Using the Apparatus. - Having opened the top and front of the box, remove the compass; and, having selected a steady table, find the magnetic meridian, taking care, meanwhile, to keep the box at a distance of a few feet, on account of the regulating magnet of the

* If the apparatus have to be carried any great distance, it is advisable to wind round the stanchions of the obalvanome and then to very carefully pack a little cotton-wool oround the just above the index, the turns of thread fibre of suspension. Wreat care must be taken in doing this, to avoid breaking the chimney of the lamp When this is done, the mercury-cups being empty, and the Ordinarily, it is lamp packed securely, the box may be inverted without the least risk. Ordinarily, it is not necessary to empty the cups in going from place to place, if they are not filled too full. To empty the cups, detach from the binding-screws of the on the left of the ebonite base, when the latter can be readily removed. galvanometer. Next remove the funnel of the lamp and the conducting. wires, and then slide out the board forming the false bottom of the box. This done, remove the brass stand and lamp from the board, and place the latter so that the side of the galvanometer-base marked " $N$." is to the north. We then have the wires of the coil running north and south, and the scale to the east of the coil. The milled head is now carefully raised until the needles are at such a height that the index will just pass under without touching the bit of paper pasted on the north-east stanchion. The galvanometer is now levelled, until the needles swing freely in the centre of the slit in the coil, and the position the index takes is noted. If this position be to the north of the $0^{\circ}$ point, turn the milled head from left to right, taking care in so doing not to lower or raise the needles. If, on the other hand, the index be to the south of $0^{\circ}$, turn the milled head from right to left. In this way, by means of the torsion of the suspending fibre, the index can be brought to $0^{\circ}$. Next adjust over the milled head the cap of the rod on which the regulating magnet slides. Place the magnet in the meridian, its marked or north pole being to the north, and slide it down the rod until the upper edge of the split tube which passes through the magnet is even with the mark cut on the side of the rod. If now the index fall off from $0^{\circ}-$ which will probably be the case-move the magnet horizontally (taking care not to raise or lower it), according to the following rules. If the index be to the north of $0^{\circ}$, move the north pole of the magnet to the west; if the index be to the south of $0^{\circ}$, move the north pole to the east. A little practice will enable the experimenter to bring the index to $o^{\circ}$ very readily. It is not necessary, however, to have the index accurately at $0^{\circ}$, so long as the degree at which it stands is noted, and is not far from $0^{\circ}$. The galvanometer is now ready for work. ${ }^{*}$

Suppose now we desire to find the relative temperature of two portions of the surface of the body-over the kidneys, for example. The two thermo-piles secured in their handles are connected thus : the positive pole of one pile is connected with binding-screws of rheostat Nos. 2 or 4 ; the positive pole of the other pile is connected with binding screw No. 3. The two negative poles of the piles are connected with each other. One of the piles is marked on the side with a white spot, and this pile should always be used for testing the relative temperature of the two parts, the other pile being placed on a part of the body not directly concerned in the observation. The reason for thus selecting one particular pile is, that the two piles are apt to vary slightly in electromotive force, in spite of all care in their construction. $t$ One pile is, therefore, placed on the arm, for example, and the other (the one marked with the white spot) is applied successively over the two kidneys. In order to tell which is the warmer of the two parts tested, we have simply to remember these rules. All currents entering binding-screws Nos. 2 and 4 , cause the index to move north ; and conversely, all currents entering at binding-screws Nos. I and 3, cause the index to move south. If, then, the pile with the white spot have its positive pole connected with binding-screw No. 4 , and the unmarked pile have its positive pole connected with binding-screw No. 3, and the former pile be placed over one kidney, and the latter on the arm, and we obtain a deflection of $10^{\circ}$ of the galvanometer scale to the north ; then, if the other kidney be the hotter of the two, we shall have an increase in the deflection to the north, on application of the pile over this kidney; but if cooler, the index will fall to the south. The faces of the piles must be applied evenly to the surface, and with the same degree of pressure. Moreover, a few moments must be allowed to elapse after the piles are applied before an observation is made. Meanwhile, the knob which forms the key (the first on the left) is kept up. When all is ready, the knob is lowered and the observation made. The first swing of the index must not be taken, but the degree at which it finally settles.

We have next to deal with the thermometric values of the deflections of the index. With the two piles in the same circuit, as above de scribed, all the knobs being down, so that the current passes directly across from one cup to another, we have the following approximate values.

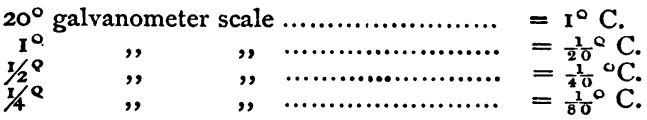

We can, therefore, read from $\frac{1}{80} \mathrm{C}$. to $11^{\circ} \mathrm{C}$., counting to the $25^{\circ}$ which forms our limit. If, now, we raise the second knob, we throw into the circuit the wire wound on spool No. I, which resistance halves the deflection; and we now have $10^{\circ}$ galvanometer scale $=1^{\circ} \mathrm{C}$. Hence

* The mercury-cups are readily filled by removing the horizontal ebonite bar above them.

+ This is simply given as a precaution. If the experimenter find, on trial, that the piles are equal in power, one may be applied over each kidney, and the difference directly noted. The writer is of course speaking with reference to future instruments. 
we measure from $\frac{1 \pi^{\circ}}{4} \mathrm{C}$. to $2 \mathrm{x} / 2^{\circ} \mathrm{C}$. Lowering this knob and raising the third one, we throw in the resistance of spool No. 2, which quarters the deflection. Therefore, $5^{\circ}$ galvanometer scale $=\mathrm{I}^{\circ} \mathrm{C}$., and we measure from $\frac{1}{2}^{\circ} \mathrm{C}$. to $5^{\circ} \mathrm{C}$.

We have thus far dealt with cases in which the relative temperature of parts at the moment of observation only was concerned. Suppose, however, we wish to make a prolonged experiment on the temperature of a part. If the unmarked pile be placed on another part of the body, it is obvious that, in an experiment of any duration, this part may alter in temperature as well as the part under observation, and hence our results may be confused. To avoid this, we use one pile only on the body, and expose the other to a constant source of heat-the current thus generated being opposed in the galvanometer to that of the pile placed on the body. It is for this purpose that the lamp and brass stand are used. The unmarked pile is fixed in the clamp at the end of the horizontal arm of the stand, the clamp being applied between the points of exit of the wires of the pile and their entrance into the binding-screws of the latter. Care must be taken that the binding-screws of the pile do not touch the brass clamp, otherwise a connection may be established across. The positive pole of the pile is connected with binding-screw No. 3, and the negative pole with binding-screw No. 4. The marked pile is connected by its positive pole with binding-screw No 2 , and by its negative pole with binding-screw No. I. It will be seen that, thus connected, the current from the unmarked pile passes in the track of the resistance coils, while that from the marked one passes directly through the cups forming the key. We have thus two separate circuits opposed to each other. In experimenting with this disposition of the apparatus, we proceed as follows. The lamp being lighted, the stand bearing the unmarked pile is placed in front of it, the face of the pile being turned towards the flame. 'The marked pile is secured to the part to be experimented upon; and, after raising the knob of spool No. 3, we lower the first knob (the key) and note the position of the index. If the current from the pile on the body be the stronger of the two, the index will, of course, be to the north of $\mathrm{o}^{\circ}$; if, on the other hand, the current from the pile in front of the lamp be the stronger, the deflection will be to the south of $0^{\circ}$. By regulating the height of the flame and the distance of the face of the pile from the lamp, we can bring the index to $0^{*}$. Any alteration in the temperature of the part under consideration will now show itself, in the case of a rise of temperature, by a deflection north; and, in the case of a fall, by a deflection south. The object of interposing the resistance of the wire on spool No. 3 is to check the "leakage" of the current of the pile placed on the body into the circuit of the other pile. A certain portion of the current of each pile will pass through the circuit of the other, instead of through the galvanometer. In the case of the pile placed in front of the lamp, this loss is of no account; but in the case of the other pile the loss is important, and must be limited. With this arrangement of the apparatus $23^{1 / 2^{\circ}}$ galvanometer scale $=\mathrm{I}^{\circ} \mathrm{C}$.

In conclusion, the writer would say that the instrument could have been made much more delicate, and, in fact, could have been improved upon in many ways, had he not endeavoured to reduce its cost to the lowest possible point.

\section{CALCULUS IN URETHRA OF A CHILD.}

H. SPARROW, aged 4 years, was admitted into the Home for Sick Children, Sydenham, on December I9th, I874, with retention of urine. For several days, it appears, he had manifested symptoms of great irritability of bladder. Upon examination, there was found to be priapism, with an elongated prepuce, which was distended with urinary excretion. There was constant stillicidium urinæ. The bladder was distended, and painful upon manipulation. much swollen and cedematous. The countenance was distressed and anxious; pulse frequent. My colleague Dr. Bird kindly administered chloroform, when a catheter was inserted into the preputial orifice, but could not be introduced into the meatus urethre. The prepuce (rather than circumcision) was slit up by means of a curved bistoury, and just within the urethra was cliscovered a small round calculus, firmly impacted, giving rise to the retention. After passing a bent probe beyond the calculus, it was at length hooked, and ejected with a certain amount of force, causing it to fall upon the floor of the room. Its character was phosphatic. A catheter was then passed, and the cherdistended bladder relieved of its contents. After the application of two sutures to the wound, the penis was enveloped in oiled lint, and the child was put to bed, when he almost immediately fell into a tranquil sleep. $\mathrm{He}$ is now convalescent, although not yet discharged from the Home. SPENCER T. SMYTH, M.D., F.R.C.S.,

Honorary Surgeon to the Home for Sick Children, Sydenham.

\section{CLINICAL LECTURE}

\section{ITCH IN PRIVATE AND IN PUBLIC PRACTICE, AND ITS TREATMENT.}

BY TILBURY FOX, M.D., F.R.C.P.,

Physician to the Department for Skin-Diseases of University College Hospital.

Gentlemen,-There are certain differences in the cases of itch that come under our treatment in public and in private practice respectively, to which I wish particularly to direct your attention. By public practice, I mean such as hospital, infirmary, and Poor-law practice, amongst the poorer classes. The matter is one of practical importance to you. You know that, in describing scabies to you, I do not follow the usual method of books, and divide the disease into papular, vesicular, and pustular scabies, and so forth; but I speak of the disease as consisting in an essential element or lesion, the acarus in and with its furrow, and certain accidental concomitants, which result as consequences of the irritation set up, and the scratching practised for the relief of the latter; of, in fact, the acarian furrow and imbedded acarus, and the results of irritation. These latter vary in kind, and include hyperæmic papillæe and follicles, vesicles, pustules, and excoriations, etc. Now, in private practice amongst the better classes, the differences in cases of scabies, as compared with those observed in hospital practice, are those of degree, not kind, and have reference chiefly to the accidental concomitants, and only slightly to the essential lesion of scabies.

In private practice, cases are occasionally met with equal in severity to any that are seen in public practice; but, on the other hand, as the rule, they are not so severe, and the disease is not so extensive, and very frequently in priz'ate practice instances come under observation in which the accidentals of scabies are scarcely if at all marked. There are a certain amount of itching, and an acarus or two here and there, and nothing more; and such cases are often erroneously diagnosed. There are many instances of scabies only a slight shade worse ; a few acarian furrows, with a few papulations.

The variations are due to several causes, chiefly to the observance of greater cleanliness, the seeking of medical advice earlier (so that the disease has not time to put on the aspect of severity), and to the better nutrition, amongst the better to do, as compared with the poor classes. Cleanliness has greatest influence, because it is a great check to the development, and migration from part to part, of the acari; and malnutrition amongst the poor favours the development of the pustular concomitants; and, lastly, the longer the disease lasts, the greater, of course, is the scratching. When want of cleanliness, much scratching, and malnutrition go together, the worst cases of scabies occur, and they may now and then, as I have said, be met with in private practice. But, inasmuch as private patients are more cleanly than public ones, seek advice earlier, and are well fed, scabies amongst them occurs in its least expressed form. But even when the disease has existed some time, it is surprising how slightly marked the disease is in some cases, on account of the extreme cleanliness observed, and the repeated washings practised by private patients.

It is with these slighter cases of scabies that I wish to deal specially - with those in which a solitary or a few acari are present, and very little else. A hasty observer may readily overlook the nature of such cases as those to which I now refer more particularly. I occasionally see instances of scabies which, at first sight, would seem to be instances of pruritus simply. There are two circumstances, however, about them, which should always put you upon your guard. The one is the seat of the pruritus-viz., the front of the abdomen, the penis, the inner and upper part of the thigh, and the front of the forearms; and the other is the occurrence of the pruritus especially, or perhaps only, at night, when the sufferer gets warm beneath the clothes. If careful examination in such cases be made, a reddish papulation may be detected along the upper line of the penis, or a solitary acarian furrow at one of the interdigital spaces or about the wrist; and this may not be readily found. I have often detected after careful search a stray furrow concealed by some of the little folds of skin in the interdigital spaces, which had escaped observation for awhile. About the forearm may or may not be a few very delicate papulations that require, for their clear detection, that the skin should be looked at obliquely. Of course I mean that, in the cases I describe, acari have been actually extracted from these solitary cuniculi. There may be no eruption anywhere but on the penis, one or two acarian furrows being seated there. I have known such cases complicated by glandular swellings in the groin, and mistaken for syphilis; but, if careful examination be made, 